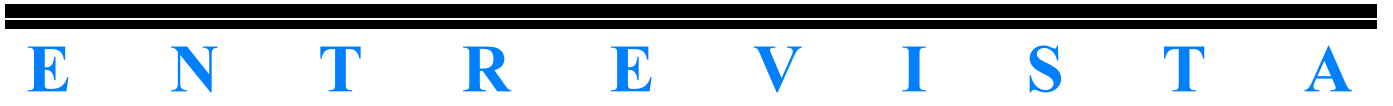




\section{ENTREVISTA A ROBERTO J. VERNENGO}

Tu obra muestra la amplitud de tus intereses filosóficos, aunque es fácil notar en ella cierta predilección por las investigaciones semánticas y sintácticas, típica de lo que algunos llaman la «escuela analítica de Buenos Aires». Sería interesante reconstruir la trayectoria que te ha llevado por esos caminos. ¿Cómo se despertó tu interés por la filosofía en general y por la del derecho en especial? ¿Que autores y maestros han influido tu sistema de pensamiento?

Quiero creer que los intereses filosóficos son un aspecto de las cosas que te interesan en la vida en general. Preguntarse, así de sopetón, qué entienda uno por filosofía, o por filosofar, tiene algo de paradójico. Por filosofía se han entendido las más variadas cosas. Algunas quedan excluidas: una actividad puramente física, como una práctica deportiva, difícilmente pareciera tener algo que ver con la filosofía. Pero las acciones del amor o las atrocidades de una guerra exhiben a veces rasgos que nos llevan a pensar y, por ende, a filosofar en algún sentido. Por otra parte, cada cual, en el transcurso de su vida, piensa sobre muchas cosas; muchas de ellas nos parecen hoy, aunque no ayer, filosóficamente irrelevantes. Por cierto que, desde siempre, los que se consideran filósofos alguna idea abrigan sobre el objeto de sus preocupaciones, aunque ello no sea siempre decisivo para lo que hacen: algunos, ¡hasta quieren cambiar el mundo! ¿Qué tal si el filósofo que sea llegara a la conclusión, conclusión que no ha faltado en la historia del pensamiento, de que la filosofía es tarea vana o imposible? $\mathrm{O}$, más enérgicamente: que carece de existencia y es tan poco sustancial como una alucinación. Si uno para saber qué hace tiene, para colmo, que rever su propia vida -tarea no siempre cómoda y muchas veces engorrosa-, preguntarse por qué uno se ha desvelado por problemas filosóficos se convierte en un enigma filosófico que agregar al repertorio de interrogantes que no dejan vivir tranquilo. A mí me han interesado -y en buena medida, me siguen interesando- cosas como la música, al punto que en algún momento pensé que mi destino era la composición. Otra, de la cual no me he desprendido del todo, es la literatura y la poesía. De alguna manera advierto que se trataba no sólo de ponerme en claro sobre el sentido de lo que uno hace -una pregunta tan retórica 
y pretenciosa como preguntarse por el sentido de la vida en general-, sino de cultivar ciertas dudas y ciertas respuestas que necesitaban pasar por el tamiz de la discusión y el control racional. Que ello sea filosofía no es del todo claro. Pero música, poesía, filosofía eran cosas ligadas a la necesidad de una comunicación ordenada. Y ¿qué eran esos instrumentos tan variados y contingentes con los que nos comunicamos e intentamos transmitir lo que nos importa? Hasta ahora no sé muy bien qué comunica la música, aunque el poder de sus mensajes suela ser insuperable. Pero tan pronto tenemos que cotejar la validez de lo que suponemos interesante o importante se impone alguna reflexión sobre el lenguaje, visto éste primeramente en su aspecto superficial, fonético y musical, hasta atisbar luego esquemas compartibles de racionalidad: las lógicas y sus presupuestos.

Tuve la suerte en el Colegio Nacional de Buenos Aires -el colegio secundario de la Universidad de Buenos Aires- de encontrar estímulos para muchas de esas cosas. No puedo olvidar que al iniciar los estudios de inglés, el primer texto que se nos propuso fue The waste land, y que en literatura castellana, además de las raciones copiosas de clásicos, se nos invitó a leer textos que acababan de aparecer, como El jardín de senderos que se bifurcan de Borges, mientras que en literatura francesa transitábamos desde Rolando y Roncesvalles, a través de Racine y Molière, hasta los últimos poemas de Éluard y de Breton. En el terreno de la filosofía, Carlos Astrada y Vicente Fatone, que habían sido discípulos de Heidegger y de Whitehead respectivamente, nos iniciaron en una manera de ingresar en ese terreno que era realmente prometedora: había que leer los textos originales mismos. Y así, con mis compañeros, recorrimos los párrafos arduos de los Prolegomena kantianos, algún diálogo platónico y páginas de Ortega y de Husserl.

En lógica, se nos impuso entonces -hablo de los años de la Segunda Guerra Mundial- el manual de Pfänder que suponía una cierta familiaridad con la fenomenología.

Intenté, concluido el secundario, entrar en la Facultad de Filosofía. Pero el panorama en la Universidad de Buenos Aires, en esos años del primer gobierno de Perón, no era estimulante. La carrera de Derecho ofrecía otros alicientes, sobre todo profesionales. Resultó, sin embargo, que desde los primeros días de mi ingreso a la carrera de Derecho me encontré con quienes serían desde entonces mis maestros: Carlos Cossio y Ambrosio L. Gioja. El tipo de enseñanza que practicaban era distintivo y, de alguna manera, ahondaban en la huella de los autores en que me había iniciado en el secundario. Tanto Cossio como Gioja aspiraban a elaborar una teoría del derecho de fundamento fenomenológico y, para agregar a la novedad, de tinte existencial, rótulo que se adjudicaba entonces al pensamiento heideggeriano. Hete aquí que, bajo la denominación de «filosofía del derecho» o de «teoría del derecho», se nos hacía estudiar a Husserl y Heidegger, de quienes circulaban traducciones efectuadas, en un castellano algo esotérico y 
para su estudio en la carrera de Derecho, por E. Langfelder, un discípulo de Kelsen. Y, sobre todo, se nos ponía directamente en contacto con el pensamiento kelseniano. Kelsen era visto «como el filósofo del siglo» en el campo del Derecho, según decir de Cossio, quien había trabajado categorías kelsenianas desde su temprano estudio, de los años 30, sobre el concepto de revolución; y Gioja terminaba su tesis doctoral sobre la noción de sistema y de norma fundamental en Kelsen. La introducción al pensamiento de Kelsen era entonces la práctica tradicional de la universidad: a diferencia de muchas otras partes, donde se tomaba noticia de algunas ideas de Kelsen a través de comentarios sucintos y críticos, se nos obligaba a familiarizarnos con la Reine Rechtslehre de manera minuciosa. Ello tenía un inmediato efecto beneficioso: el estudio de las materias dogmáticas se hacía enormemente sencillo, al enmarcarlas en un conjunto de conceptos teóricos que creíamos dominar. Lo cierto es que, para un trabajo teórico que se nos había solicitado en una asignatura de Derecho penal, escribí una monografía sobre la retractación en los delitos contra el honor. Mi empeño consistió en buscar cuáles serían las Rechtssätze descriptivamente adecuadas para pensar esa extraña institución: una excusa absolutoria que convertía a las acciones consideradas delictivas y típicas en impunibles. Y, para la doctrina tradicional, un delito penal sin sanción era una contradicción flagrante. Cossio, al tanto de ese trabajo, lo hizo publicar, siendo mi primera publicación teórica.

Pero los intereses de las exposiciones magistrales de Cossio y de los seminarios de Gioja (que se efectuaban fuera de la Facultad, dado que las discrepancias políticas se habían hecho agudas) se extendían a nuevos terrenos: por un lado, los movimientos realistas, en Escandinavia y en los Estados Unidos, respondían muy cercanamente a preocupaciones que inspiraban a Cossio; por el otro, la cuestión de la lógica del Derecho se hizo acuciante. Cossio había propuesto, desde un punto de vista neo-kantiano, una interpretación de la teoría pura como una lógica del Derecho, una lógica trascendental relativamente formalizada. Gioja proponía una interpretación paralela, inspirándose en la lógica formal y trascendental de Husserl. La aparición en ese entonces (1951) del ensayo de G. von Wright, «Deontic Logic», provocó el derrumbe crítico de esas interpretaciones, en que se habían formado durante quince años varias promociones de abogados y juristas. Se hizo conciencia la necesidad de profundizar las lógicas que creíamos dominar. De pronto, Husserl y sus seguidores nacionales fueron reemplazados por Russell, Tarski, Carnap. El último seminario en que participé en Buenos Aires, antes de mi traslado a Europa, fue un seminario dirigido por Cossio -luego publicado-, sobre un análisis fenomenológico de la noción de norma, que von Wrigth tuvo presente mucho después. Por el otro lado, junto a un conjunto abultado de traducciones, escribí un ensayo en que intentaba un análisis, hoy diría ideológico, del realismo norteamericano (Frank, Llesvellyn, etc.): me aparecía, pese a su radicalismo metodológico, como un movimiento político decididamente conservador. 
Por ese entonces -comienzos de los años 50-, había concluido mis estudios de Derecho e intenté iniciarme en las actividades académicas. Por otra parte, inicié mi actividad como abogado, sobre todo en asuntos penales, en el despacho que habían abierto G. R. Carrió y L. Landaburu. Pero por razones no muy académicas -un tío mío, marino, había sido quien había detenido a Perón-, mi ingreso a la Facultad de Derecho era utópico. Por sugerencia de Cossio, me fui a trabajar y estudiar a Suiza, donde tuve la suerte de seguir cursos con H. Kelsen en Ginebra y seminarios con M. Heidegger, en Basilea y Zürich, entre otros. También trabé amistad con Octavio Paz, quien elaboraba entonces su libro sobre la poesía, «El arco y la lira», donde brotaban en cada página los problemas tradicionales de la filosofía. Por otra parte, la aparición de las obras póstumas de Husserl y, sobre todo, los ensayos más recientes de Heidegger obligaban a revisar la interpretación un tanto sesgada que llevábamos de la fenomenología y de la entonces llamada antropología existencial. En ambos pensadores se hacía sentir la carencia de fundamentos lógicos más rigurosos, como los que sustentaban los ensayos de autores que sólo entonces comencé a frecuentar: Wittgenstein, entre otros.

Regresé a la Argentina en 1958, para incorporarme a la cátedra de filosofía del Derecho de Ambrosio L. Gioja. Allí se inicia mi carrera académica, en la que luego recorrí todas las etapas: desde ayudante de cátedra de Carlos Cossio, hasta profesor adjunto de A. Gioja, para luego, a fines de la década del 60, alcanzar la titularidad de la cátedra de filosofía del Derecho como catedrático y director del Instituto de Filosofía del Derecho. En 1976 tuve que abandonar el país -bajo el gobierno militar se me acusó nada menos que de haber permitido discusiones con marxistas en el instituto que dirigía: efectivamente lo había hecho y había organizado un ciclo de conferencias sobre lógica y derecho en el que participaron C. Cossio y E. Marí-, residiendo en México hasta 1983. En México fui recibido con los brazos abiertos por la Universidad Autónoma Metropolitana y por la Universidad Autónoma Nacional en sus Institutos de Investigaciones Filosóficas y Jurídicas. Fue por entonces que comenzaron las relaciones más estrechas con pensadores españoles: especialmente con Elías Díaz, que había gestionado una protesta de solidaridad ante mi expulsión de la universidad argentina.

Manolo Atienza, entre tanto, había efectuado una primera síntesis de mis trabajos y la de otros pensadores argentinos en su estudio sobre la filosofía del derecho.

Al regresar a la Argentina, en 1983, con la restauración de la democracia, se me restituyó mi cátedra y proseguí regularmente mi carrera académica, hasta ser designado en 1995 profesor emérito e investigador principal del Consejo Nacional de Investigaciones Científicas. Esto, en lo que hace a los peldaños de una carrera donde las preocupaciones docentes fueron intensas; me correspondió organizar, ante el fallecimiento de Gioja, la carrera docente, escribiendo varios ensayos sobre problemas de la pedagogía jurídica; 
los departamentos de postgrado y doctorado en la Facultad de Derecho y desempeñar otros cargos que me pusieron en contacto con problemas por los que no había tenido ocasión de interesarme realmente con anterioridad. Es que, con lo que nos tocó vivir en la Argentina en la década del 70, la década del60, pese a todas las convulsiones académicas en que participábamos, parecía una era idílica.

Lo cierto es que, desde mi regreso a la Argentina desde Europa, en 1958, me encontré ante un panorama nuevo en los estudios de filosofía jurídica, inaugurado con iniciativas originales de Gioja. Así, me correspondió dictar, en 1958 y los años posteriores, seminarios de doctorado sobre textos de Wittgenstein y de Austin, y luego sobre el pensamiento ético de Kant, cuyos Prolegomena, Kritik der praktischen Vernunft y Metaphysik der Sitten recorríen sucesivos seminarios cuyas actas fueron luego publicadas. Por otra parte, reinicié mis publicaciones con un ensayo sobre La cientificidad de la jurisprudencia. El carácter de ciencia de las disciplinas dogmáticas era un presupuesto no analizado de la teoría del derecho en que me movía: tanto para Kelsen como para Cossio, el punto de partida de la reflexión filosófica sobre el derecho era la ciencia jurídica, el conocimiento teórico del derecho. En él se constituía el objeto de conocimiento, pensaba Kelsen, y en ella se hacían explícitos reflexivamente los procesos creadores de Derecho, para Cossio. Pero las novedades lógicas que nos llegaban desde todas partes, en los años 50, obligaron a poner sobre el tapete ese presupuesto anteriormente indiscutido. En 1960, Gioja organizó, en el Instituto de Filosofía del Derecho, un seminario sobre el problema de la Grundnorm kelseniana; es decir, planteaba el problema, no sólo de la constitución del objeto teórico, sino el del carácter sistemático de las disciplinas que pretendían estudiar el Derecho. Me correspondió iniciar dicho seminario con un trabajo sobre La función sistemática de la norma fundamental, que encaró la interpretación epistemológica, kantiana o no, que se atribuía a esa problemática norma. Mis conclusiones escépticas al respecto -planteadas antes de la publicación del trabajo del propio Kelsen sobre el carácter ficticio de la Grundnormtuvo alguna repercusión. Alchourrón y Bulygin iniciaron una prolongada investigación sobre el carácter de sistema que se atribuía a conjuntos de normas o a un derecho todo, investigación que culminó, una década después, con la publicación del importantísimo libro sobre sistemas normativos. Por mi parte, los problemas internos de la teoría ecléctica del derecho en que me movía (una teoría general de inspiración kelseniana, con todas las reservas que un análisis lógico de sus categorías suscitaba), me llevaron a investigar las estructuras elementales del lenguaje jurídico, principalmente a nivel del lenguaje teórico. Así publiqué el ensayo sobre Formation rules for legal lenguages, que a partir de una reinterpretación de los Geltungsbereiche normativos de $\mathrm{H}$. Kelsen -un concepto que siempre había aparecido como teóricamente descolgado-, me introducía en problemas quizás puramente lingüísticos (continuado luego en mi libro sobre La interpretación 
literal de la ley y en varios ensayos, como el relativo a Formalization of legal languages. Las novedades que Chomsky había aportado a la lingüística tradicional, aunque tradicionales en algunos respectos, como las estructuras profundas evocadas por Humbold, me parecieron contribuir interesantemente en el problema semántico de la asignación de sentido a expresiones normativas; también, para disipar algunos problemas crónicos de la filosofía jurídica provenientes de equívocos y abusos del lenguaje, entre ellos la extraña dicotomía entre un «ser» y un «deber-ser», lógicos u ontológicos, cuyo segundo término, el meneado «deber-ser» es una denominación mal formada en nuestros lenguajes. Pero, con la preocupación por las estructuras lógicas y categoriales de los lenguajes o jergas jurídicas, se me plantearon varios problemas que, desde entonces, me han ocupado: la aplicación e interpretación del derecho (que analicé en un libro sobre Introducción a los problemas de la interpretación en derecho, publicado defectuosamente y con variadas tergiversaciones en México).

Llego, pues, a la titularidad de la cátedra de filosofía del Derecho -«titular» en la Argentina, equivale al catedrático español, mientras que el titular español en la Argentina es un profesor «adjunto»- en 1970, con una grave herencia: Gioja había fallecido y el grupo de investigadores que se había mantenido alrededor de su cátedra tuvieron que ser rescatados, frente a la perturbadora situación que la universidad pasaba, no sólo por razones políticas externas, sino por crisis suscitadas por la irrupción del pensamiento marxista y por los desarrollos escandalosos de la lógica, que de una respetada e inerte lógica clásica había pasado a escindirse en una multitud de lógicas divergentes, entre las cuales las variadas lógicas deónticas o normativas. Un factor nuevo se agregaba a esta múltiple problemática: las novedades que para el Derecho aportaba la informática.

2. En los albores de la informática jurídica, cuando yo mismo trataba de acceder a algún conocimiento de un tema que muchos tomaban por fantasía, vos ya habías publicado artículos acerca del tema y te habias constituido en pionero y propagandista de esa línea de investigación. Hoy, la mayoría de las aplicaciones de la informática jurídica son realidad cotidiana y su examen se ha vuelto predominantemente tecnológico. ¿Qué relación ves entre la informática jurídica y la teoría del Derecho? ¿Qué aportes, en tu opinión, puede observarse o esperarse que ambas disciplinas intercambien entre ellas?

Sucedió que los aportes de las gramáticas transformacionales y de las lógicas normativas que se iban desarrollando, más las primeras contribuciones de la informática al almacenamiento de datos, a fines de los sesenta, parecían girar alrededor de ciertos problemas centrales desatendidos por los juristas. Estos aceptaban despreocupadamente el carácter sistemático de los Derechos positivos, que creían de alguna suerte lógicamente consistentes, cuando no completos. Pero lo cierto es que, para el jurista práctico, para el 
juez y el administrador, los Derechos positivos aparecen como conglomerados heterogéneos de normas, definiciones, declaraciones políticas, etc., todo ello adobado con dosis abundantes de redundancias e inconsistencias. Los juristas, en rigor, consideran Derecho positivo al resultado decantado de un proceso más o menos consciente de abstracción y de reconstrucción teórica. El hecho de que fuera posible almacenar en la memoria electrónica de una computadora una enorme cantidad de información textual normativa $y$, sobre todo, de que se dispusiera de recursos de búsqueda enormemente eficaces y poco costosos, hizo pensar de inmediato que se pudiera recoger así el material normativo producido por numerosos órganos en los estados modernos. Lo propuse al Ministerio de Justicia de mi país, aunque no se disponía todavía de los recursos técnicos necesarios. Sólo poco después, y en colaboración con Italia, fue posible iniciar la recopilación de las numerosas y variadas normas del derecho argentino federal en un sistema de consulta. Hablo de los años iniciales de la década del 70. La Argentina fue uno de los primeros países que pudo contar con esas facilidades que aún prosperan en el Sistema Argentino de Informática Jurídica.

La mera perspectiva de realizar esa labor de almacenamiento requería de soluciones a varios problemas previos, de índole tradicionalmente filosófica. Las normas positivas son redactadas en las formas más variadas; los filósofos, desde Frege, consideraban que, frente al tenor superficial de los enunciados, normativos o no, cabía captar un sentido o significado ideal, como elemento definitorio de las clases de enunciados equivalentes o sinónimos. Pero, frente a normas prescriptivas, la noción de significado, si se la relaciona con alguna mención, se hace oscura, pues en los usos interesantes jurídicos, las normas no funcionan como referencia de estados de cosas reales. Por otra parte, los lenguajes con que se manejaban las computadoras por ese entonces, provenientes de intereses matemáticos, como el COBOL, no parecían favorables a la captación de expresiones normativas no formalizadas que sólo se prestaban a las operaciones lógicas proposicionales más elementales. Formalizar las expresiones normativas de los Derechos positivos, para hacerlas aptas para su manejo por computadoras, suponía plantearse rigurosamente el asunto de los lenguajes y la lógica a que esas expresiones debían traducirse y sujetarse. Las funciones que las normas jurídicas positivas parecen desempeñar en la práctica jurídica, especialmente en la judicial, no respondían al modelo simple de una demostración mecánica de un teorema matemático, demostraciones para las cuales ya se habían desarrollado por ese entonces demostradores de teoremas. Por añadidura, juristas, prácticos y teóricos, ignoraban alegremente los desarrollos que se habían producido, después de la guerra, en terrenos tales como la teoría de juegos y de la decisión y volvían -como sucedió en Alemania, en los años 70, con Esser- a viejas tesis tomadas de la hermenéutica bíblica o histórica de Schleiermacher y Dilthey. Justamente Cossio, en sus libros sobre el Derecho judicial, de los 40, había abundado en la explotación de esas propuestas hermenéuticas, 
recurso que me parecía y me parece una invitación a la irracionalidad en la práctica decisoria. Para colmo, Perelman y sus epígonos cuestionaban la validez del razonamiento lógico formal en el terreno jurídico, llegándose a la extraña situación de que un pensador como Kelsen, defensor toda su vida del racionalismo en el campo del derecho, llegara a desconfiar de la validez de una inferencia lógica entre normas. Parecía claro que tales criterios hermenéuticos -y otros recursos análogos, como la calificación de ideológica de toda tesis jurídica por algunos escritores franceses supuestamente progresistas- eran incompatibles, por irracionales (i.e.: predicaban un antilogicismo, generalmente derivado de un soberano desconocimiento de lo que la lógica contemporánea ofrecía), con el empleo de computadoras que, muy modestamente, se atenían a reglas lógicas estrictas y evitaban todo recurso a intuiciones, valoraciones, ideologías, metáforas y otras estratagemas de igual irracionalidad.

La teoría general del Derecho paradigmática hasta la década del 79 -a saber: la kelseniana con un background filosófico positivista- no estaba preparada para hacerse cargo de las novedades que la cibernética introducía. No se trataba solamente del problema práctico, terreno en el cual los juristas -por lo menos en la etapa de la mera cibernética documental- pronto supieron sacar provecho de las ventajas que las computadoras y las bases de datos ofrecían en la búsqueda de información normativa. Al proponer yo muy modestamente la posibilidad de almacenar datos jurídicos en una memoria electrónica, no faltó algún pensador, devoto entonces de Althusser, que me acusara de «jibarismo» teórico y no sé de cuántos otros pecados ideológicos. La situación real era extraordinariamente primitiva: recuérdese la importancia que se daba, y quizás aún se da, a los esfuerzos mnemotécnicos en la enseñanza del Derecho, como si estuviéramos aún en una cultura analfabeta. Pero además las categorías tradicionales que explotaba la teoría general del Derecho, muchas de ellas de oscuro origen histórico en especulaciones de jurisconsultos romanos y de canonistas medievales, parecían especialmente inútiles cuando se intentaba reconstruirlas para aprovecharlas en un lenguaje de programación computacional. Más aún: al hacerse necesarios análisis formales más penetrantes con tal objetivo, se comprobó que muchas de las supuestos conceptos teóricos con que se manejaba la teoría del derecho eran inconsistentes o requerían el previo esclarecimiento de múltiples presupuestos que la jurisprudencia había esquivado poner sobre el tapete. Piénsese que una noción que se puso de moda y a la que se dio gran importancia, la de derechos humanos, apenas puede ser concebida aún hoy dogmáticamente, en forma satisfactoria, con los artefactos tradicionales de la teoría del Derecho, recurriendo los autores a artilugios arcaicos (dualismos, «derechos morales», etc.) o teorías ad hoc. Aún hoy, cuando nos dedicamos a elucubrar sobre otros derechos y obligaciones, como los derivados de los movimientos ecológicos, advertimos que el concepto de derecho (subjetivo) y de deber jurídico no bastan para pensar teóricamente el nuevo 
campo jurídico que se nos abre. Hasta he leído hace poco, en una declaración sobre una pretendida ética universal que propugnarían teólogos de variadas religiones, que tendríamos que hacemos cargo de deberes morales frente al cosmos: para mi forma de pensar, condicionada por una enseñanza clásica del Derecho, se me hace difícil concebir deberes míos con respecto a una remota galaxia o un quásar. Por otra parte, la introducción de rutinas computacionales en la práctica del Derecho y en su teoría volvió a plantear el problema del modelo con que pensamos el lenguaje, el lenguaje en general y los especiales lenguajes, técnico y formal, que usan los Derechos positivos y las teorías jurídicas. Pues se había hecho corriente el extrapolar conclusiones extraídas del análisis de los lenguajes naturales, en las llamadas filosofías del lenguaje y en las disciplinas lingüísticas, al campo del derecho. Ello contaba, por cierto, con un antiguo antecedente: pensar al Derecho como un conjunto de órdenes o imperativos implicaba considerarlo un tipo de acto lingüístico. Mi primera sorpresa, en un ensayo de inicios del 60 (Recht und Sprache), fue advertir que había tipos de actos lingüísticos y de expresiones verbales, ya destacadas por Hume, que tenían virtudes constitutivas, como las declaraciones vinculantes en Derecho. Los análisis anclados en las características de los lenguajes naturales, pese a su incipiente calculabilidad a partir de las gramáticas generativas iniciadas por Chomsky, no correspondían precisamente a cálculos lógicos propuestos en lógicas formales de diverso tipo. Ciertos fenómenos lingüísticos, como la distinción entre enunciados declarativos y enunciados modales (prescriptivos y otros), habían introducido cuñas tajantes en la epistemología del conocimiento jurídico, donde se repetía dogmáticamente, más allá de sus consecuencias lógicas patentes, que el Derecho se daba en un mundo propio, un mundo normativo o, como se decía con mala gramática castellana, un mundo del deber-ser. Y así como había encontrado una manera de interpretar plausiblemente la teoría kelseniana de los Geltungsbereiche, a la luz de las reglas de formación de un lenguaje técnico postulado, encontré que las técnicas de análisis generativo de Chomsky permitían aclarar o disipar problemas pretendidamente ontológicos que, a la postre, derivaban de defectuosos análisis de las estructuras profundas de los lenguajes normativos. La supuesta isomorfía entre estructuras lingüísticas y estructuras jurídicas me pareció, luego, una exageración simplificadora: el derecho no es únicamente lenguaje, aunque puedan darse paralelismos interesantes entre los fenómenos lingüísticos -el discurso como secuencia de actos de habla- y la realidad del derecho. Otro cantar es que atendamos a los aspectos ideales de las expresiones normativas, su significado proposicional, y su eventual correspondencia con las características necesarias o esenciales que atribuyamos a lo que denominamos derecho. En las aplicaciones de la cibernética al Derecho los problemas atinentes a la formalización e interpretación del Derecho se han acrecentado: no estamos del todo seguros que las normas jurídicas, en sus múltiples aspectos, hayan sido suficientemente reconstruidas para 
su manejo cibernético eficaz; no sabemos muy bien cuál sistema inferencial, qué lógica, aplicar a esas expresiones.

Estos problemas se han acrecentado con la posibilidad de aplicar en el Derecho los recursos de la inteligencia artificial. Al fin y al cabo, algunos de los primeros sistemas expertos, como el Taxman de McCarthy, fueron construídos para hacer frente a problemas jurídicos rutinarios. Los sistemas cibernéticos permiten hoy análisis automáticos de textos normativos y derivaciones deductivas conforme a múltiples sistemas lógicos. Fuera del interés grandísimo de esos recursos para la práctica del derecho, viejos problemas de la filosofía jurídica han tenido que ser replanteados con mayor precisión. En ese respecto, creo necesario destacar que la jurisprudencia lleva la delantera a la especulación moral, donde la aplicación de programas cibernéticos no es usual.

3. En cualquier momento, un ser humano puede mirar hacia atrás y proponerse una descripción sintética de su actividad, cualquiera sea el aspecto de ella que desee enfatizar. Muchos no lo hacen, acaso para no deprimirse. No es ése tu caso, ya que tu obra plantea el problema inverso: lo que los franceses llamarían l'embarras du choix. Te pido justamente esa elección: ¿describirías (hasta ahora) el meollo de tu obra, y qué criterios emplearías para seleccionar esa descripción frente a otras posibles?

Creo -aunque seguramente estoy equivocado y, quizás mañana yo mismo sostenga algo distinto- que mi preocupación central, en el terreno de la filosofía del Derecho y de la filosofía tout court, es el asunto de la racionalidad y de su núcleo tradicional: la razón. Al fin y al cabo, he creído y sigo creyendo que un campo objetivo, como el Derecho, es susceptible de ser conocido científicamente, fuera de que, en la realidad histórica, mucho de lo que se nos ofrece como ciencia jurídica sea desdeñable para la mirada analítica del filósofo. Y la ciencia implica, como construcción conceptual consistente, algún módulo lógico explícito, y como práctica social, ciertas pautas compartidas de racionalidad. No puedo menos que recordar mi sorpresa cuando un oscuro y minúsculo problema penal se desvanecía y se abría teóricamente cuando se echaba mano, para explicarlo, de unas pocas categorías teóricas y formales de la Reine Rechtslehre. En rigor, guardo siempre la esperanza de que, frente a intratables problemas políticos y sociales, encontremos recursos teóricos suficientes para esclarecerlos. La razón ha sido, en la filosofía moderna, el terreno propio de la filosofía, el terreno en que afloran los viejos problemas metafísicos de la verdad y de la ontología. Pero también ha sido, tradicionalmente, un campo de Agramante: aún hoy no sabemos muy bien de qué hablamos cuando invocamos la razón y nos pretendemos racionales, $\mathrm{o}$, como ha vuelto a ponerse de moda, cuando aspiramos más modestamente a ser por lo menos razonables (confieso que no me gusta mucho la distinción entre racionalidad y razonabilidad, conceptos con connotaciones bastante dispares en los diversos lenguajes: ¿qué hay de 
común, por caso, entre la razón que invocara Ortega y la razonabilidad que Rawls nos recomienda, en 1993, en Political Liberalism, como una suerte de virtud personal de quienes estén dispuestos a cooperar en términos equitativos, aceptando ciertas normas como buenas para lograr una sociedad justa?). La mera existencia de una razón práctica pone a los filósofos en actitud bélica. En los escritores que predican morales dialógicas y entre juristas desconfiados de la lógica, la razonabilidad ha adquirido sólido prestigio, es un útil subterfugio. Pero la distinción entre una objetividad racional (i.e.: científica) y una objetividad razonable (i.e.: meramente consensual) es de nuevo una recaída en el irracionalismo y, en derecho, en una anarquía disimulada en alguna legitimidad hipotética derivada de supuestos consensos morales. Algo de esto fue tratado en el libro Pureza metódica y racionalidad en la teoría del derecho, que publicara junto con Ulises Schmill en 1984.

Ahora bien: uno ha visto traslucirse el rostro enigmático de la razón en muchos de los problemas filosóficos que hemos heredado. Ayer nomás parecía que no se podían encarar los problemas de la vida social, las cuestiones jurídicas, si no se partía de una ontología satisfactoria en que el derecho encajara como una entidad específica. Con esos pretendidos problemas ontológicos se entreveraban problemas más viejos aún, como el de la distinción entre moral y derecho, o entre un derecho natural y los derechos positivos. Las relaciones supuestas entre valores (morales o políticos) y normas jurídicas o Derecho se dirimían en el ámbito de aquellos dualismos recibidos.

Luego, se exigía replantear y encarar los problemas epistemológicos que suscitaba un conocimiento del Derecho con pretensión científica y, por ende, con un discurso teórico sobre el derecho pretendidamente tan verdadero como algunas de las ciencias tradicionales, ya no la física que, en la Edad moderna, se había encaminado por terrenos matemáticos que espantaban a los juristas, pero sí como la medicina o la historia, disciplinas admitidamente científicas aunque «blandas». Cundió, frente a la embestida del marxismo en la década del 60 y al reproche de ideologismo político que se atribuyó no sólo a las normas jurídicas positivas, sino a los intentos descriptivos de múltiples juristas, un escepticismo radical: no sólo la supuesta jurisprudencia teórica no habría sido ciencia en sentido serio alguno, sino que, por alguna fatalidad ontológica inexplicable, el Derecho mismo no sería susceptible de sistematización alguna teórica acertada.

Pero estos problemas, ontológicos, epistemológicos y, a la postre, lógicos (i.e.: sintáctico-semánticos), tenían repercusiones prácticas: la aplicación y la efectividad del derecho parecían territorios ante los cuales los filósofos del Derecho, creyentes en la posibilidad de una teoría, en sentido contemporáneo, del derecho, se declaraban impotentes o, por lo menos, minusválidos. De ahí que, en mi carrera intelectual, una vez alcanzada una cierta tranquilidad con respecto a los contenidos mínimos de una teoría general del derecho -que expuse con fines didácticos hacia 1979, en mi Curso 
de teoría general del Derecho, un libro pensado como una síntesis, no de mis preocupaciones, sino de los logros alcanzados en más de medio siglo de aplicación a la práctica científica dogmática de los análisis formulados a partir de la doctrina kelseniana, y también en el Curso de filosofía del trabajo que se editara en México en 1981)-, me dedicara a investigar los problemas de la aplicación del Derecho, sobre todo en lo que hace a la interpretación del derecho. Empecé con la monografía sobre La interpretación literal de la ley (1971) y continué con el libro sobre interpretación del Derecho y los ensayos sobre análisis de construcciones teóricas de la ciencia del Derecho (por ejemplo: Obligación y contrato (1979) y ensayos de circulación interna sobre taxonomías jurídicas). Pero, frente a la tesis hoy corriente de que todo es interpretación -una generalización por lo menos apresurada -, y a los lugares comunes, repetidos hasta el hartazgo, sobre la indefinición, imprecisión, vaguedad, fuzziness y otros inconvenientes de los lenguajes jurídicos o del Derecho mismo, me interesaron dos cosas: por un lado, las estructuras lógico-lingüísticas que subyacen al pensamiento teórico de los juristas, $\mathrm{y}$, por el otro, los criterios de decisión y las estructuras preferenciales que dan sentido a los procesos de interpretación y aplicación del Derecho. Vale decir: de su producción o creación social.

Un viejo problema ontológico -la distinción entre la moral o las morales y los derechos positivos- pudo ser replanteado desde una perspectiva lógica: sea cual fuere el tipo de relación que se postulara entre ambos dominios, por lo general no se atendía suficientemente a las consecuencias analíticas que uno $\mathrm{u}$ otro tipo de relación propuesta implican. Pero las consecuencias derivables dependen de la lógica efectivamente utilizada. Y se advirtió que muchas de las polémicas tradicionales al respecto permanecían ajenas a esta elemental estrategia. En 1988 publiqué en Granada Moral y Derecho: sus relaciones lógicas, donde se planteaba el asunto.

Desde 1990 hemos publicado, junto con el matemático y lógico brasileño Newton da Costa -conocido por sus trabajos sobre sistemas paraconsistentes, entre otros muchos-, varios trabajos en que tratamos de encarar esta cuestión: Derecho, moral y preferencias valorativas (1990), Lógicas normativas, moral y derecho (1991), y ahora, en este número de Doxa, el ensayo sobre Lógicas paraclásicas y un análisis del razonamiento jurídico. Por mi parte, mis convicciones frente al asunto de las relaciones entre derecho y moral quedaron asentadas en Law and morality: an analysis of their possible relations, ensayo que leí en la reunión de 1992, en Reykjavik, de la IVR, y cuyas tesis me parecen aún hoy acertadas.

El problema de la racionalidad en el Derecho ante todo requiere poner sobre el tapete los problemas lógicos, tanto para un análisis suficiente del lenguaje jurídico como para encarar problemas epistemológicos importantes, los relativos a una sistematización consistente de datos normativos. En el pensamiento contemporáneo el asunto tiene sus bemoles: a partir del pensamiento de Georg von Wright, con una permanente inquietud con respecto 
a la estructura lógica de los sistemas normativos -a partir del Deontic logic de 1951 hasta los Six essays in philosophical logic de 1996-, se han puesto a prueba diversas lógicas para establecer las estructuras racionales del pensamiento jurídico. En mi país y en mi generación, el pensamiento de Carlos Alchourrón, que acaba de morir prematuramente, ha sido inspirador: Alchourrón, en definitiva, considera que un Derecho positivo cuenta con una estructura racional en cuanto las normas que son consecuencia clásica de otras normas integran el orden jurídico que se considere (véase su trabajo sobre On law and logic leído en la reunión de Bolonia, en 1995, de la IVR). Pero hay muchas otras propuestas: desde algunas que parecen resignadas a admitir una cierta idiosincrática lógica propia del derecho (como Francisco Miró Quesada, a cuya propuesta me refiero en Lenguaje jurídico y lógica jurídica, 1990), o echan mano de diversas lógicas divergentes. Hoy la referencia obligada es a las lógicas no monotónicas y a las lógicas fuzzies. Traté de hacer un balance del estado de la cuestión, a principios de la década del 70, en Ideologías, lógicas y lógicas de la acción, aparecido en México, y luego, ya en 1987, en Derecho y lógica: un balance provisorio, aparecido en el Anuario de Filosofía del Derecho que se publica en España. He vuelto, una y otra vez, sobre estos temas, por ejemplo, en Rechstrationalität und rationale Rechtswissenschaft (1984), Conceptual analysis, systematization and rationality in legal science (1984), Formalization in legal languages (1986), Logik und eine phänomenologische Auslegung der Reinen Rechtslehre (1988), About an empowerment theory of legal norms and some related problems (1989), Racionalidad juridica y lógicas normativas (1990), Legal rationality and divergent normative logics (1991), Legal taxonomics and conceptual analysis (1989), Lógicas normativas y la reconstrucción del razonamiento jurídico (1992), Sull'interpretazione logica degli enunciati giuridici (1993), Les règles morales et leur création (J 995) y El discurso del derecho y el lenguaje normativo (1995).

A veces, estos desarrollos se han efectuado en actitud polémica: Kelsen's Rechtssätze as detached statements (1986), Sobre algumas relaçotógicas entre sistemas normativosjurídicos e morais (1989), Legal rationality and divergent normative logics (1991), Est-ce le droit un système? (1991), y con N. Da Costa, Logical models for the reconstruction of legal reasoning: fuzzy and paraconsistent logics (1994).

Pero el cariz de la racionalidad que, me parece, importa en derecho es el de la racionalidad en la toma de decisiones. La interpretación de las normas ha de ser la expresión de una decisión, individual o colectiva, racional. Y si las normas son vistas como expresión de preferencias, como valores como se solía decir, las normas mismas deberían ser el resultado de decisiones racionales. Por lo menos ésa es la pretensión de los sistemas jurídicos -liberales y democráticos- modernos y la aspiración que mantenemos desde la Edad de las Luces. Ahora bien, como se sabe, la racionalidad de una decisión colectiva tiene sus limitaciones, muchas de las cuales han sido encaradas 
por los Derechos positivos recurriendo a artilugios que comienzan a mostrar sus grietas. Ello es notorio en los sistemas procesales que buscan superar esa situación tradicional admitida.

En todo caso, la problemática de la interpretación en Derecho, sin incurrir en exorbitancias à la Derrida, tiene que hacerse cargo de los resultados inquietantes de la teoría de la decisión, en especial, los planteados por Arrow y Amartya Sen respecto de las conclusiones de la social choice theory. Me parece que algunos puntos interesantes para la teoría del Derecho han sido traídos a luz por las exposiciones de la economic theory of law, desde los trabajos de G. Becker y R. Posner, resultados que, pese a las graves objeciones filosóficas que han suscitado, merecen ser atendidos. Algo he podido decir al respecto en el trabajo sobre Interpretación del Derecho (1994) que se publica ahora en la Enciclopedia Iberoamericana de Filosofía.

4. Un tema recurrente en el pensamiento iusfilósofico es el de la crítica epistemológica, a saber si la ciencia del Derecho (o, como algunos dicen modestamente: el saber de los juristas) tiene categoría científica o puede llegar a tenerla. Alguna vez has expresado una opinión positiva acerca de este interrogante. ¿Qué criterio de demarcación empleás? ¿Cómo clasificarías las ciencias de tal modo que la taxonomía incluyera la jurídica, y en que clase la pondrías? ¿Cuáles son, a tu juicio, las ventajas y los defectos que la ciencia del Derecho tiene frente a la epistemología escogida como punto de referencia, y de qué modo esperás aprovecharlos?

Fui formado en la creencia de que la ciencia del Derecho -sus múltiples disciplinas, y en especial las referidas al Derecho penal y al Derecho civil- tenían indiscutiblemente carácter de un conocimiento acumulativo institucionalmente transmitido. Jaspers, a quien Cossio aludía, llegó a decir que se trataba de un saber constrictivo (aunque luego caracterizó a las ciencias modernas como falibles, incompletas, parciales, frente a una filosofía como saber total); Husserl nos había convencido que cualquier dominio objetivo, con la suficiente elaboración, podía ser objeto de un conocimiento estricto, es decir: matemático. Kelsen, por su parte, o, por o menos el Kelsen anterior a su traslado a América, partía, como buen neo-kantiano, del hecho dado de una ciencia instituida. Y ¿qué duda cabía ante el pasado milenario de la jurisprudencia? $\mathrm{O}$, en países como la Argentina, ¿cómo dudar ante el hecho de que los estudios jurídicos eran requisito ineludible de toda práctica social reconocida o de una carrera política admisible? Sin embargo, pronto advertí que entre los juristas reconocidos mediaban discrepancias sustanciales; en especial, ello era notorio entre penalistas, cuyas obras magistrales estaban dedicadas en buena parte a la polémica contra penalistas defensores de otras teorías del delito. Y también me sorprendió que para explicar fenómenos al parecer sencillos, como la posesión o los títulos de comercio, se nos recomendara frecuentar múltiples teorías entre sí incompatibles: cien teorías distintas para explicar la naturaleza de la letra de cambio no podían 
pretender ser todas verdaderas. Para paliar semejante situación, Cossio inventó la tesis que la ciencia del Derecho tenía esencialmente un carácter polémico. Pero, ¿polémico con quién? Los juristas teóricos, desde sus cátedras, parecían convivir sin mayores dificultades ante conjuntos tan desperdigados de doctrinas, doctrinas que los abogados prácticos y los jueces utilizaban sin resquemor como les conviniera. En una oportunidad, recurriendo a técnicas de análisis de contenido, a un grupo de compañeros se nos ocurrió estudiar en qué diferían los enfoques teóricos de civilistas de declarada tendencia iusnaturalista, frente a civilistas proclives al positivismo. Encontramos que entre las ideologías asumidas y las actitudes teóricas había poca o nula relación: positivistas y iusnaturalistas encaraban de manera bastante similar los datos; los presupuestos teóricos utilizados por los unos y los otros se caracterizaban, ante todo, por su carácter tradicional y poco explícito y, luego, por su insólita semejanza.

Años después, en la Argentina y en muchos otros países de tradición romanista, el carácter casi sagrado de la jurisprudencia tradicional hacía crisis. Por un lado, se advertía que el discurso pretendidamente verdadero de la jurisprudencia era más que nada un arma retórica utilizada pragmáticamente para defender tales o cuales intereses. Por el otro -aspecto destacado sobre todo por los juristas que comenzaban a leer a Marx y a los marxistas franceses-, se hizo un lugar común bautizar a la jurisprudencia tradicional de discurso ideológico reaccionario. Los juristas tradicionales, por lo que se comprobó, se abstuvieron de participar en tales contiendas y continuaron produciendo, imperturbables, los densos tomos de interminables tratados. Parecía, pues, que la polémica supuestamente ínsita en la ciencia jurídica se cumplía en un campo de batalla dividido e incomunicado. Efectivamente, pasadas las críticas décadas del 60 y el 70, la producción de ciencia del derecho se sigue cumpliendo conforme a indiscutidas pautas tradicionales. Por cierto que, de vez en cuando, un libro suscitaba inquietud: así fue en la Argentina, con el Tratado de Derecho Penal de Sebastián Soler, en la década del 40, o con el libro sobre Arbitrariedad y Recurso Extraordinario de G. R. Carrió, en la década siguiente. Pero eran excepciones.

La filosofía analítica introdujo una cuña perturbadora: metodológicamente hablando, las disciplinas jurídicas parecían relativamente ingenuas. O, en otros casos, cabía mostrar que incurrían en falacias, inconsistencias, confusión de niveles de lenguaje, males que la teoría de la ciencia entonces en boga condenaba implacablemente. Por añadidura, las estructuras teóricas y las construcciones teóricas con que nos manejábamos plácidamente fueron puestas en cuestión. La primera que cayó fue la Grundnorm kelseniana que su propio padrino (dado que Kelsen repudiaba su paternidad) había descartado. Con ella se derrumbaban ideas prestigiosas: la unidad de los órdenes jurídicos, la estructura jerárquica y la supremacía de las constituciones positivas, las funciones sistemáticas de la jurisprudencia. Me correspondió sembrar alguna de estas inquietudes, con mi trabajo sobre La función sistemática 
de la norma fundamental, en 1960. Mal podíamos sospechar entonces que otras funciones, expresas o latentes, que la ciencia del derecho cumplía desde siempre iban a ser puestas en la picota y fuertemente repudiadas.

La muerte y resurrección de la vieja, vieja ciencia del Derecho es historia conocida: tachada de cómplice de cuanta injusticia se había llevado a cabo (así, por ejemplo, en América Latina era baldada como bastión de la dependencia) y de impotencia ideológica culposa, el desprestigio de la ciencia del derecho alcanzó su cenit hacia fines del 70. Luego se ha ido recuperando; las casas de estudio la siguen transmitiendo y difundiendo y, acaso, produciendo. Jueces, políticos y abogados confían en ella para salvaguardar la seguridad política y, con el paulatino ocaso de los regímenes socialistas y la instauración de sistemas económico-políticos liberales, de una ciencia que se pretendió asumiera un rol crítico en cada sociedad, hemos vuelto a una ciencia satisfecha con alcanzar una descripción adecuada del sistema normativo que sea. Obviamente esta jurisprudencia neutral y puramente descriptiva no se ajusta demasiado a los modelos teóricos de las ciencias duras: ¿qué conjunto de hipótesis cabía verificar o falsificar, cuando los juristas ni tenían noticias de que una teoría se configuraba como un conjunto de hipótesis en un modelo deductivo? ¡Y ahora se veía en la jurisprudencia un discurso dirigido a un auditorio compuesto por jueces, abogados, funcionarios judiciales, etc., una casta profesional formada por los llamados «operadores jurídicos», como se dio en llamar a este sector social! En lugar de buscar la verdad o la justicia, la jurisprudencia intentaba ahora recopilar formas argumentativas destinadas a lograr consenso en algún respecto por los mentados operadores jurídicos o discutir interminablemente pseudo-cuestiones morales relativas a la legitimidad de tal o cual Derecho positivo.

En otros términos: las contiendas alrededor de la legitimidad de la jurisprudencia qua ciencia, que solían dirimirse anteriormente alrededor de planteos ontológicos, da paso a una tendencia en que lo que importa es la eficacia del discurso científico del Derecho como motivador de políticas decisorias. Los criterios de demarcación, como vos decís, que solían atenerse a pautas supuestamente objetivas: ¿el Derecho es un dato fáctico social? ¿el Derecho es un conjunto de normas implantadas por legisladores humanos y nada más, o bien es un conglomerado articulado de valores, comportamientos sociales y normas promulgadas? Y hasta: ¿el Derecho es un dato inefable captable, a veces, en alguna intuición con que captamos la justicia o injusticia de una situación?, han perdido interés teórico. Es fácil comprobar que aún aquellos juristas que hacen artículo de fe -pues de eso se trata- de que el derecho es una manifestación del valor «justicia» (u otros) en el marco de la conducta social pautada, poco se preocupan porque sus manifestaciones lingüísticas reflejen los presupuestos ontológicos postulados; así, en América Latina, los programas «tridimensionales», como el propuesto por M. Reale, poco atienden a la constitución de sus enunciados teóricos y a sus condiciones de verdad, dadas tales supuestas múltiples dimensiones ontológicas. 
Esta suerte de estrabismo ontológico, según el cual, para una comprensión o explicación suficiente del Derecho, se requiere visualizarlo tanto en sus aspectos normativos como en sus aspectos axiológicos y fácticos, es, me parece, una herencia del dualismo que el iusnaturalismo, inculcado durante varias décadas por el pensamiento eclesiástico en España, ha sembrado en la especulación jurídica en nuestros países. De ahí también el maridaje entre supuestas teorías morales y la teoría jurídica. El reciente ensayo inicial de una teoría general del derecho de $\mathrm{M}$. Atienza y J. Ruíz Manero lo admite desde las primeras páginas. No ha sido tal la tradición del positivismo analítico que se desarrolló en la Argentina con la obra de Cossio, de Gioja, de Alchourrón, de Bulygin, de Farrell, la tuya y la mía, tradición mucho más fiel a la problemática de la unidad objetiva del conocimiento jurídico del derecho y su punto de partida en conjuntos normativos positivos.

No tengo, pues y en principio, resquemor con respecto a la posibilidad de un conocimiento científico del derecho. Pareciera, también en principio, que no hubiera razón atendible para denegar esa posibilidad frente a cualquier configuración objetiva que encontremos o que constituyamos.

Dudo, en cambio, de que frente a los diversos panoramas en que los juristas dicen encontrar al derecho tengamos que resignarnos a una forma paradigmática de teorización, en especial, cuando la misma es tomada, por unos, de las ciencias duras físico-matemáticas, y por los otros, de dominios tales como la psicología y la historia, donde prosperarían los procedimientos hermenéuticos. Creo, más bien, que dada la delimitación borrosa del tema objetivo que la jurisprudencia encara caben diversos niveles de teorización. Al fin y al cabo, muchas de las elaboraciones jurídicas que aún hoy utilizamos no sobrepasan el nivel de una glosa con livianas pretensiones sistemáticas, similar a la dudosa tarea científica que practican los críticos literarios. En otros casos, como en la doctrina penal, se construyen modelos teóricos complicados a los cuales se trata, luego, de adaptar los datos normativos y fácticos recibidos. Pero, por lo general, la labor teórica, echando mano de viejos conceptos supuestamente originados en los jurisconsultos romanos y los civilistas franceses, en nuestra tradición continental comienza con esquemas taxonómicos: la ciencia del Derecho es, sobre todo, un conocimiento clasificador. Por cierto que las taxonomías jurídicas, por lo que he podido ver en mis trabajos sobre Taxonomías jurídicas y clasificaciones jurídicas (1988), suelen ser poco rigurosas desde un punto de vista lógico y abrevan en viejos dualismos filosóficos que persisten en el tradicional lenguaje jurídico, v.gr. la distinción imprecisa entre dolo y culpa, entre responsabilidad y culpa, entre capacidad e incapacidad, entre facultad y derecho subjetivo, entre otros. En estos aspectos, como se advierte en la producción de la generación más reciente de juristas en mi país, la conciencia adquirida de los problemas epistemológicos que esta ciencia de validez preponderantemente retórica, pero con aspiraciones tradicionalmente más altas, y los requerimientos que al conocimiento teórico del Derecho imponen 
las exigencias de la cibernética, permiten abrigar esperanzas de que alcanzaremos un conocimiento teórico del derecho más sólido; esto es, verificable, objetivamente cuestionable y, quizás, socialmente útil. El contar con un fundamento general teórico para tales ciencias me parece que es el mérito grande y la iniciativa importante del pensamiento kelseniano, pues, obviamente, tenemos que tener un conjunto de categorías metacientíficas (lógicas y otras), para que el conocimiento actual, «rapsódico» del derecho (como decía Kant), se convierta en un discurso teórico sistemático. Me parece que la actitud crítica que estuvo de moda en la década pasada, aunque tenga mucha razón en sus reproches políticos a la ciencia jurídica tradicional, no provee suficientemente de esos fundamentos necesarios o los esquiva frívolamente.

5. Desde el punto de vista teórico, siempre has asumido una posición de escepticismo crítico, ligada al no cognitivismo. ¿Corresponde concretamente a tu pensamiento negar todo valor de verdad a cualquier enunciado ético, o aceptarías alguna verdad relativa? En caso afirmativo, ¿cuáles serían los parámetros en lo que tal verdad pudiera predicarse? $Y$ en cualquier caso, ¿de qué modo fundarías tus propias actitudes morales?

Entiendo que te referís a cuestiones morales. Confieso que, habiendo visto pasar tantas y tantas concepciones éticas -intuicionismos y cognoscitivismo de la más variada índole y generalmente dogmáticos-, fundadas supuestamente en posturas epistemológicas antagónicas, guardo una cierta reserva -si se quiere llamarla escéptica- con respecto a las doctrinas morales circulantes. Entendámonos bien: como cualquier persona tengo mis convicciones morales y políticas, convicciones morales y políticas que no pretendo sean siempre de validez universal e inmutables. En ese sentido, me parece que los credos y recetas morales que se difunden valen como otras tantas opiniones, respetables o no, según quién sea el que las sustente y cuáles sean sus consecuencias previsibles. Me refiero especialmente a morales prescriptivas. No dudo que cabe hablar con sentido de valores morales, de normas morales, de sistemas morales: cabe dar de tales nociones explicaciones bastante satisfactorias. Así las teorías de la preferencia y de las elecciones (subjetivas o sociales) permiten entender racionalmente lo que se suele afirmar de entidades más tenues o inasibles, como los valores. De la literatura en que uno se formó en esos terrenos: Scheler, Ortega, Hartmann, poco ha quedado. La condena que Heidegger llegó a formular contra el concepto de valor, Wert, viéndolo como una blasfemia que distorsionaba la comprensión de las cosas (de los entes) a partir de su ser, parece cumplirse acabadamente en el campo del derecho, donde todo se intentaba explicar recurriendo a una noción de valor, tan prestigiosa como oscura. El valor de la persona humana, el valor del derecho en sí mismo, el valor de la justicia y otros muchos valores eran tópicos usuales de moralistas y juristas. Para colmo, tan pronto se bajaba de la especulación metaética al nivel de códigos 
morales prescriptivos concretos, nos encontrábamos con un legalismo exagerado que ni el más perverso de los positivistas ideológicos imaginado por Bobbio se hubiera atrevido a sostener. Curiosamente, esa tendencia subsiste: se ve en alguna moral -la propuesta, materialmente o procesalmente, por cada quien- el fundamento de validez de todas las demás normas sociales.

Las normas jurídicas, para buena parte del pensamiento jusnaturalista expreso contemporáneo (que poco influye sobre las construcciones teóricas de los juristas), y del pensamiento jusnaturalista qui n'ose pas dire son nom, como en Dworkin, Nino y buena parte de la escuela crítica francesa, debieran tener fundamento moral para tener fuerza obligatoria, para existir como normas. Pero, a poco, como en las teorías dualistas sobre los derechos humanos, encontramos que esas normas morales, esos derechos morales, requieren para hacerse efectivos, para llegar a ser en algún sentido, manifestarse como normas jurídicas positivas. Sólo que, entonces, la existencia de tales normas morales se convierte en meramente postulada; las normas jurídicas positivas, en cambio, sólo son admitidas como tales si pueden pasar el test de algún proceso de verificación de su producción y subsistencia.

Pero me preguntás por la verdad de los enunciados éticos. Si por tales entendemos a normas en sus usos prescriptivos, claro está que ciertas nociones de verdad -como correspondencia- no son viables para tales prescripciones. Si pensamos a las normas como proposiciones ideales, podemos, incurriendo en un platonismo bastante inútil hablar de verdad de normas, en cuanto son deductivamente demostrables de las normas supremas que consideramos punto de partida. Si las normas expresan preferencias, bueno, no parece tener mucho sentido pensarlas como dotadas de verdad objetiva, pues las preferencias son relaciones entre estados de cosas y nadie postula preferencias universales en tal marco. Pero me parece que en todo este asunto hay varias confusiones: si las normas, en su expresión prescriptiva, son analizadas lingüísticamente, resulta que constituyen expresiones complejas, como he destacado desde Modelos formales y generativos de enunciados normativos (1972): muchas veces, algunas de las oraciones imbricadas en esos enunciados normativos complejos aceptan o requieren de verificación empírica. Es el caso, por lo común, de las apódosis fácticas de normas hipotéticas. Pero, aun en ellas, los consecuentes deónticamente modalizados contienen enunciados declarativos susceptibles de verdad o falsedad empírica (por correspondencia). Por añadidura, muchas veces confundimos en el lenguaje corriente y aun en el lenguaje técnico de la jurisprudencia, las normas prescriptivas con los enunciados que predican algo de esas prescripciones. Y esas proposiciones descriptivas, como quería Kelsen, las Rechtssätze, pueden ser verdaderas por correspondencia (con algunas reservas). Al respecto, me parece que mi trabajo, publicado en España en 1993, sobre Deberes prescriptivos y deberes descriptivos pone alguna claridad en este berenjenal. 
Ahora, si se trata de verdad por consistencia, aceptándose alguna lógica adecuada para los lenguajes normativos, y postulándose alguna propiedad hereditaria transmisible por procedimientos lógicos -llámesela verdad, validez, o lo que sea-, no habría dificultad en hablar de la verdad, por decir así, de los enunciados éticos. Pero me sigue pareciendo que se trata de un recurso más de persuasión retórica, pues la verdad de los preceptos morales o jurídicos poco tiene que hacer con la sólida verdad de las ciencias empíricas y con la inmutable verdad de las disciplinas formales (como quisiéramos creer).

Quienes hablan alegremente de verdades morales suelen ser esquivos, por lo común, para explicitar las lógicas a las que recurren. En cuanto a mis propias actitudes morales, creo que se fundarían en las creencias, preferencias y, ¿por qué no?, gustos y deseos que cultivo. Los mismos me han sido inculcados y, a lo largo de mi vida, los he ido modificando. No me parece que las actitudes morales mías, en lo que hace a la vida cotidiana e, inclusive a esa vida artificial que denominamos vida académica, difieran grandemente de las actitudes corrientes en personas de mi edad y formación en los países de civilización europea. Ignoro si comparto tales preferencias y creencias con hombres con los cuales no he tenido comunicación, sean caníbales del Amazonas, muslims del Irán o shintoístas fervientes en el Japón.

6. Querría ahondar un poco más en el tema de los argumentos morales, que en tu obra suelen aparecer como actitudes sustentadas por terceros sujetos. Vos mismo tendrías algunas opiniones politicas que, por ejemplo, te hacen preferir un estado democrático antes que otro fascista. Probablemente no creas posible justificar esas opiniones mediante una demostración more geometrico. Pero también es probable que opiniones de esa clase no dependan directamente de una elección emotiva. ¿Cómo explicarías tus preferencias?

Creo que he manifestado varias veces mi desconfianza ante las morales argumentativas. Otra cosa es la cuestión de la preferencia que ciertamente sustento a favor de regímenes democráticos. En mi país, desde que recuerdo, hemos transcurrido por regímenes tan diversos $\mathrm{y}$, al repasar ahora lo que hemos vivido, no puedo menos de incurrir en una suerte de relativismo histórico o cultural cuando de democracia se habla. Así, el primer gobierno de Perón, a fines del 40, ostentaba legitimidad democrática indudable: había sido elegido en comicios libres, frente a regímenes conservadores anteriores surgidos del fraude. Pero ese inicial gobierno peronista ciertamente no era un régimen liberal. Sin embargo, no puedo menos que recordar que, cuando debí vivir en Suiza, a partir de 1951, me sorprendía advertir que la vida en Suiza, rígida y reglamentada, era, en algún sentido, mucho menos democrática que la vida que se vivía en un Buenos Aires supuestamente fascista. Los estilos de vida eran demasiado diferentes como para rotularlos con las mismas categorías. La democracia helvética, para un porteño de entonces, 
era insoportable; el desorden y libertad casi libertina del porteño de entonces seguramente habrían parecido anárquicos a un suizo prolijo. Tengo muchos ejemplos similares: recientemente, en la década del 80, comprobé en Alemania Occidental que muy democráticos y liberales profesores de filosofía del derecho aceptaban resignadamente consignar su afiliación a creencias religiosas que no sustentaban por temor a la opinión académica; en España, luego del cierre del franquismo, ciertos tabúes sociales poco democráticos, como un respeto tradicional a jerarquías sociales y a figuras simbólicas, como la del rey, nos hubieran parecido, en la Argentina, impropias de una democracia. Y es notorio que democracia no significa, ni significó, nunca lo mismo en países de la región: ¿alguien se atrevería a cotejar la democracia mejicana bajo el P.R.I., con los regímenes presidenciales argentinos? O el caudillismo regional brasileño con el sistema de gobernadores provinciales de mi país? Hoy se afirma que en los países americanos rigen sistemas democráticos, como, parejamente, se sostiene con respecto a los países europeos luego de la caída del muro de Berlín. Pero así como hay poco de común entre la meneada democracia italiana y la atildada democracia sueca, y poco comparten la democracia peruana 0 paraguaya con la democracia actual argentina, preferir un estado democrático en abstracto quiere decir poca cosa, aunque no es posible actualmente declararse contrario.

Ciertamente que la preferencia por un régimen democrático no se demuestra deductivamente. En rigor, ninguna preferencia se demuestra, sino que se la padece, admite, consiente, recibe, etc. Se hace difícil, sin embargo, sostener que la preferencia por la democracia resulte de algún tipo de experiencia intuitiva, aunque, sin duda, la experiencia vital de cada uno ha sido un factor de peso en las preferencias políticas que luego se van manifestando. Además vivimos en una época en que ciertas palabras, que podrían admitir definiciones más rigurosas, están revestidas de una carga emocional tan grave que es casi imposible discutir al respecto con alguna neutralidad. Hoy, por ejemplo, la Iglesia romana ha encontrado entre sus enemigos a lo que llama «relativismo», término bajo el cual cabe entender muy variadas cosas. Es cierto que, en un plano formal y riguroso, un relativismo consecuente puede conducir a inconsistencias. Pero, a nivel del habla corriente y de los lenguajes naturales, las consecuencias catastróficas del relativismo ético se diluyen, si es que se advierten. Curiosamente, las comprobadas consecuencias nefastas de los fundamentalismos (objetivismo, etc.) morales o religiosos son tomadas poco en serio. Y si bien es claro que los regímenes tiránicos de los que tenemos memoria se han fundado -cuando han pretendido fundarse en algo- en convicciones resultantes de éticas fundamentalistas objetivas dogmáticas, se repite muy apresuradamente y sin prueba alguna que el relativismo ético lleva al totalitarismo y que es incompatible con la democracia. No puedo dejar de recordar una recomendación que recibí de H. Kelsen: para éste, la existencia objetiva de las normas 
morales era cuestionable toda vez que no existía, ni existe, una ciencia asentada de la moral. Tenemos opiniones y especulaciones morales, por cierto, pero nada más. Kelsen me sugirió, partiendo de su propia experiencia biográfica, que en aquellos regímenes políticos donde se comenzaba a hablar demasiado de la moralidad, pública o privada, como asunto primordial y se ponía de lado argumentos jurídicos o políticos, para evaluar la conducta de los ciudadanos desde una supuesta moral, lo mejor era huir preventivamente de tales sistemas opresivos. Leo también ahora, con motivo de las discusiones sobre la constitución que tiene que adoptar la ciudad de Buenos Aires -mi ciudad, que ha adquirido autonomía en virtud de una reforma de la constitución nacional- que algunos sectores religiosos proponen que en la declaración de principios o preámbulo se mencione a Dios, pues, al parecer, no mencionar a alguna divinidad implicaría algo así como fundar la democracia en la negación de Dios, sea ello lo que fuere. Recuerdo haber leído, en la literatura jurídica española, unas disparatadas propuestas similares. Resulta, empero, que la mención requerida carece de todo efecto, pues esas declaraciones no tienen efectos normativos. Más curioso me pareció leer en un esbozo de declaración universal de principios morales, proyectado por una reunión de iglesias, a instancias de Kühn -declaración que no pasa de una versión aguada de una ética kantiana- que se evitara la mención de Dios, pues se trataba de un factor de divergencia y conflicto. Algo semejante nos pasa hoy con los derechos humanos, cuya mención retórica pareciera condición necesaria para un régimen democrático. No puedo olvidar que, hace ya muchos años, un organismo de las Naciones Unidas consideró que la constitución dictada en Santo Domingo para satisfacer nada menos que a un dictador tan siniestro como Trujillo fuera considerada modelo de respeto suficiente de los derechos enunciados en la Declaración Universal de Derechos Humanos.

En definitiva: con respecto a la democracia, me gusta mucho la tesis de J. Mosterín. Sin duda, en cuanto sistema social es el menos malo de los sistemas de gobierno (Mosterín dixit); pero no por eso deja de ser un régimen con defectos. Uno de ellos es el fraude mayor o menor que tienen todos los sistemas electorales: de ahí que la representación política sea frustrante, de ahí que subsistan instituciones inútiles (como los senados), de ahí que se sacralicen los sistemas judiciales, pese a su notoria ineficiencia. Seguramente, quisiéramos creer que pautas de convivencia racionales puedan ser mejor alcanzadas bajo un régimen democrático que en un régimen autoritario donde vale la voz del amo ocasional. Pero el imperio de la razón se logra apenas hasta ahora y, en todo caso, en forma desesperadamente lenta. 